\author{
U.G. Kyle • L. Nicod • C. Raguso • D. Hans • C. Pichard
}

\title{
Prevalence of low fat-free mass index and high and very high body fat mass index following lung transplantation
}

\begin{abstract}
The aim of this study was to determine the prevalence of low fat-free mass index (FFMI) and high and very high body fat mass index (BFMI) after lung transplantation (LTR). A total of 37 LTR patients were assessed prior to and at 1 month, 1 year and 2 years for FFM and compared to 37 matched volunteers (VOL). FFM was calculated by the Geneva equation and normalized for height $\left(\mathrm{kg} / \mathrm{m}^{2}\right)$. Subjects were classified as FFMI "low", $\leq 17.4$ in men and $\leq 15.0$ in women; BFMI "high", 5.2-8.1 in men and 8.3-11.7 in women; or "very high" $>8.2 \mathrm{~kg} / \mathrm{m}^{2}$ in men and $>11.8 \mathrm{~kg} / \mathrm{m}^{2}$ in women. In $23 \mathrm{M} / 14 \mathrm{~F}$, body mass index (BMI) was $22.3 \pm 4.4$ and $20.1 \pm 4.9 \mathrm{~kg} / \mathrm{m}^{2}$, respectively. The prevalence of low FFMI was $80 \%$ at 1 month and $33 \%$ at 2 years after LTR. Prevalence of very high BFMI increased and was higher in patients than VOL after LTR. The prevalence of low FFMI was high prior to and remained important 2 years after LTR, whereas BFMI was lower prior to and higher 2 years after LTR.
\end{abstract}

Key words Bioelectrical impedance analysis (BIA) • Body composition $\cdot$ Fat-free mass $\cdot$ Body fat mass $\cdot$ Lung transplantation $\cdot$ Nutritional assessment $\cdot$ Follow-up

U.G. Kyle • C. Raguso • C. Pichard (匈)

Clinical Nutrition

Geneva University Hospital

Geneva, Switzerland

E-mail: claude.pichard@medicine.unige.ch

L. Nicod

Pneumology, Geneva University Hospital

Geneva, Switzerland

D. Hans

Nuclear Medicine, Geneva University Hospital

Geneva, Switzerland

\section{Introduction}

Recent studies have shown that lung disease (e.g. chronic obstructive pulmonary disease) are associated with general muscle dysfunction, and is not limited to the lower limbs [1]. Thus, patients with lung diseases are characterized by a sedentary life-style, tending to have a higher body fat (BF) and lower fat-free mass (FFM). However, lung transplant patients are often malnourished prior to lung transplantation (LTR). Significant weight gain is common following heart [2] and liver transplantation [3]. However, no data are available from LTR patients. Although some weight gain is desirable, excessive body fat should be avoided in this group of patients.

The evaluation of FFM and BF can aid in adapting nutrition support. The use of the square of the height in the denominator of the FFM index (FFMI) and BF mass index (BFMI) effectively eliminates differences due to height [4]. The FFMI $\left(\mathrm{kg} / \mathrm{m}^{2}\right)$ aids in determining whether lower FFM with age is due to shorter height in older subjects or changes in body composition. The aim of this study was to determine the prevalence of low FFMI and high and very high BFMI following LTR.

\section{Subjects and methods}

In 37 LTR patients body composition was measured at 1 month, 1 year and 2 years post-LTR as a part of the routine follow-up of LTR patients. Healthy volunteers, matched for age and height, were used as controls. Informed consent was obtained from all participants before being considered for LTR waiting list.

Body height $( \pm 0.5 \mathrm{~cm})$ and body weight $( \pm 0.1 \mathrm{~kg})$ were measured. Body composition was determined by bioelectrical impedance analysis (BIA). FFM was calculated by a validated BIA equation [5]: $\mathrm{FFM}=-4.104+\left(0.518^{*}\right.$ height $^{2} /$ resistance $)+(0.231 *$ weight $)+(0.130 *$ reactance $)+[4.229 * \operatorname{sex}(\operatorname{men}=1$, women $=0)]$. Cross-validation of BIA with DXA was excellent, $r=0.986$, $\mathrm{SEE}=1.72 \mathrm{~kg}$, technical error $1.74 \mathrm{~kg}$. 
Ranges of FFMI and BFMI were derived from polynomial regression equations from our healthy subjects $(n=5635)$ [6]. The FFMI and BFMI were divided into four categories low, normal, high which and very high, which correspond to World Health Organization categories for low weight $\left(<20 \mathrm{~kg} / \mathrm{m}^{2}\right)$, normal weight (20-25 kg/m ${ }^{2}$, overweight $\left(25-30 \mathrm{~kg} / \mathrm{m}^{2}\right)$ and obesity $\left(>30 \mathrm{~kg} / \mathrm{m}^{2}\right)$.

FFMI $\left(\mathrm{kg} / \mathrm{m}^{2}\right)$ was "low" at $<17.4$ (men) and $<15.0$ (women); "normal" between 17.5 and 19.7 (men) and 15.1 and 16.6 (women); and "high" at $>19.8$ (men) and $>16.7$ (women). BFMI $\left(\mathrm{kg} / \mathrm{m}^{2}\right)$ was "low" at $<2.4$ (men) and $<4.8$ (women); "normal" at 2.5 to $5.1 \mathrm{~kg} / \mathrm{m}^{2}$ (men) and 4.9 to 8.2 (women); "high" at 5.2 to 8.1 (men) and 8.3 to 11.7 (women); and "very high" at $>8.2$ (men) and $>11.8 \mathrm{~kg} / \mathrm{m}^{2}$ (women).

\section{Statistical analysis}

Descriptive statistics are expressed as mean $\pm \mathrm{SD}$. Unpaired $t$ tests was used to assess differences between volunteers and pre-LTR measurements. Chi-squared test was used to study the differences between malnutrition indicators. Statistical significance was set at $p<0.05$ for all tests.

\section{Results}

The BMI for men and women LTR $(22.3 \pm 4.4$ and $20.1 \pm 4.9$ $\left.\mathrm{kg} / \mathrm{m}^{2}\right), \mathrm{FFM}(50.8 \pm 6.9$ and $35.3 \pm 5.0 \mathrm{~kg})$ and FFMI $(17.5 \pm 2.0$ and $13.7 \pm 2.0 \mathrm{~kg} / \mathrm{m}^{2}$ ) were significantly lower than those for healthy men and women $(26.4 \pm 3.3$ and $23.6 \pm 2.5,60.4 \pm 6.4$ and $42.8 \pm 3.0,20.5 \pm 1.5$ and $16.4 \pm 0.8$, respectively) at the time of pre-LTR evaluation. Weight, FFMI and BFMI increased progressively throughout the 2 years of follow-up in women and until 2 years in men and remained stable thereafter. BFMI was nonsignificantly higher thereafter.

One month after LTR, $37.1 \%$ of LTR patients were underweight (BMI $<18.5 \mathrm{~kg} / \mathrm{m}^{2}$ ), compared to $80.0 \%$ with a low FFMI (Table 1). None of the volunteers were underweight. At 1 year, 39.4\% were low FFMI, whereas $33 \%$ of patients showed a low FFMI at 2 years.
At 1 month post-LTR, $2.9 \%$ of patients were obese (BMI $>30 \mathrm{~kg} / \mathrm{m}^{2}$ ), but $8.6 \%$ were in the very high (obese) BFMI range. The prevalence of very high BFMI increased from year 1 to year $2(15-26 \%)$. In comparison, $15 \%$ patients were obese at 2 years. Thus, BMI underestimated the prevalence of FFM depletion and very high BFMI and was inadequate in evaluating the nutritional status in LTR patients.

\section{Discussion}

No studies have reported the prevalence of low FFMI and high and very high BFMI in LTR patients. Both low and high BMI are significant risk factors for nonsurvival after transplantation [6].

The weight increases during the first year were responsible for normalization of FFM, in half of the patients (from 80 to $39 \%$ ). With FFMI, subjects with differing age and height can be compared. Two-thirds of patients reached age- and heightexpected quantities of FFM after 2 years. However, the increases in weight led not only to beneficial effects of normalizing FFM, but also to increased obesity following LTR. BF increases were less than half of increases reported in LTR patients [3].

Our data contradict those from studies in post-liver andheart transplantation patients that do not show increases in FFM, except in the presence of exercise. Hussaini et al. [3] reported a decrease in FFM and weight and stable FFM at 12 and 24 months, in spite of significant weight gain $(+11.5$ and $7.8 \mathrm{~kg}$, respectively) in liver transplant patients. Plank et al. [8] found that liver transplant patients lost $10 \%$ of body protein reserves during the first 2 weeks after transplantation. $\mathrm{BF}$ returned to preoperative levels within 3 months, whereas only one half of the protein lost in the early postoperative phase was regained by 12 months. Braith et al. [9] found lower FFM $(-2 \mathrm{~kg})$ in heart transplant patients whose weight was stable 2 months after transplantation. At 3 and 6 months post-heart transplantation, FFM continued to decrease in inactive heart transplant patients, but increased in patients who followed a program of resistance exercises.

Table 1 Prevalence of low and high fat-free mass index $(F F M I)$, and high and very high body fat mass index $(B F M I)$ in volunteers and patients pre-(PRE) and at 1 month, 1 and 2 years post-transplantation

\begin{tabular}{|c|c|c|c|c|c|c|}
\hline & VOL & PRE & Mo-1 & Yr-1 & Yr-2 & $p$ value \\
\hline \multicolumn{7}{|l|}{ FFMI } \\
\hline Low $\%, \mathrm{n}$ & $5.4 / 2$ & $67.6 / 23$ & $80.0 / 28$ & $39.4 / 13$ & $33.3 / 9$ & Chi square 54.2 \\
\hline High $\%, \mathrm{n}$ & $51.4 / 19$ & $17.6 / 6$ & $5.7 / 2$ & $18.2 / 6$ & $33.3 / 9$ & $\mathrm{df}=8, p<0.0001$ \\
\hline \multicolumn{7}{|l|}{ BFMI } \\
\hline High $\%, \mathrm{n}$ & $45.9 / 17$ & $20.6 / 7$ & $25.7 / 9$ & $36.4 / 12$ & $40.7 / 11$ & Chi square 19.9 \\
\hline Very high $\%, \mathrm{n}$ & $5.4 / 2$ & $11.8 / 4$ & $8.6 / 3$ & $15.2 / 5$ & $25.9 / 7$ & $\mathrm{df}=12, p<0.07$ \\
\hline
\end{tabular}

$d f$, degrees of freedom; VOL, volunteers; Mo, month; $Y r$, year 
Limitations of the study

BIA measurements have occasionally been criticized. In this study, simultaneous measurement by BIA and DXA showed a mean bias of $-0.4 \pm 1.5 \mathrm{~kg}$, range -3.9 to $3.4 \mathrm{~kg}, r=0.987$, $\mathrm{SEE}=1.5 \mathrm{~kg}$. Therefore there is good agreement between BIA and DXA.

\section{Conclusion}

The prevalence of low FFMI was high in LTR patients prior to and was still significant 2 years after LTR, whereas BFMI was lower prior to and higher 2 years after LTR. Nutritional assessment in LTR patients should include body composition measurements to determine low and high FFMI and BFMI.

Acknowledgement We thank the Foundation Nutrition 2000Plus for financial support.

\section{References}

1. Gasker HR, Lencer NH, Franssen FM, van der Vusse GJ,
Wouters EF, Schols AM (2003) Striking similarities in systemic factors contributing to decreased exercise capacity in patients with severe chronic heart failure or COPD. Chest 123(5):1416-1424

2. Ragsdale D (1987) Nutritional program for heart transplantation. J Heart Transplant 6:228-233

3. Hussaini SH, Oldroyd B, Stewart SP, et al (1998) Effects of orthotopic liver transplantation on body composition. Liver 18:173-179

4. Baumgartner RN, Koehler KM, Gallagher D, et al (1998) Epidemiology of sarcopenia among the elderly in New Mexico. Am J Epidemiol 147:755-763

5. Kyle UG, Genton L, Karsegard L, Slosman DO, Pichard C (2001) Single prediction equation for bioelectrical impedance analysis in adults aged 20-94 yrs. Nutrition 17:248-253

6. Kyle UG, Schulz Y, Oupertuis YH, Pichard C (2003) Body composition interpretation: contribution of fat-free mass index and body fat mass index. nutrition (in press)

7. Snell GI, Bennetts K, Bartolo J, et al (1998) Body mass index as a predictor of survival in adults with cystic fibrosis referred for lung transplantation. J Heart Lung Transplant 17:1097-1103

8. Plank LD, Metzger DJ, McCall JL, et al (2001) Sequential changes in the metabolic response to orthotopic liver transplantation during the first year after surgery. Ann Surg 234:245-255

9. Braith RW, Mills RM, Welsch MA, Keller JW, Pollock ML (1996) Resistance exercise training restores bone mineral density in heart transplant recipients. J Am Coll Cardiol 28:1471-1477 